\title{
Psychosocial Health: Hidden Effects in the Water Supply and Sanitation Environment
}

Ira Kusumawaty $^{* 1}$, Ari Siswanto ${ }^{2}$

${ }^{1}$ Department of Nursing Politeknik Kesehatan Kemenkes Palembang, Indonesia

${ }^{2}$ Department of Architecture Faculty of Engineering Sriwijaya University, Indonesia

*Corresponding Author: irakusumawaty@poltekkespalembang.ac.id

Article history

\begin{tabular}{llll}
\hline Received & Received in revised form & Accepted & Available online \\
18 July 2021 & 22 January 22 & 31 January 2022 & 31 January 2022 \\
\hline
\end{tabular}

\begin{abstract}
Accomplishing the needs of water and sanitation often encounters obstacles in certain family groups, touching on the complexities of psychosocial health problems. The facts show that attention to the impact of fulfilling clean water and inadequate sanitation on psychosocial health is often neglected. It is important to explore water availability and sanitation impact on psychosocial health. This qualitative research was conducted using a phenomenological study approach, involving 5 families living on the banks of a river in Palembang. The in-depth interview method was carried out until data saturation was reached, observations and field notes were carried out during the data collection process. Data collection was analyzed using the Colaizzi method to obtain four themes, namely stress due to not getting access to clean water, economic difficulties that cause emotional stress in accessing clean water, compulsion to use available water and discomfort using public sanitation facilities. The policy needs to facilitate certain community groups to access the needs of clean water and sanitation by taking into account the psychological aspects of the community. The collaboration of community leaders is needed in accelerating access to clean water and sanitation that respects the dignity of the community more.
\end{abstract}

Keywords: water access, environment hidden impact, psychosocial health

\section{Introduction}

Psychosocial health as a component of health in relation to water and sanitation in the SDG's (Sustainable Development Goals) era has been formulated. This is a challenge that is not simple because there are many components that can be seen in its implementation [1]. Literature on the psychosocial impacts of water has emerged recently but is still very limited. Whereas psychosocial impacts related to water insecurity should receive special attention [2], [3]. Various evidence shows that water insecurity results in emotional distress, anxiety, depression [3], [4], frustration, worry, anger, and helplessness [5], [6], [2], [7]. However, less attention is paid to psychosocial impacts and more focused on the context of impact assessments or evaluations.

Psychosocial health generally emphasizes individual perceptions and responses to social and environmental conditions and status [8]. A key component of psychosocial health is the way individuals and communities assess their environmentin terms of living conditions and ability to adapt. What is interesting in this understanding process is the person's perspective on the dangers and suffering due to stress in the environment and the lack of potential they have to protect themselves [9]. Psychosocial pressure is considered a concept that affects the dynamic relationship between environmental demands, individual resources to cope with it and the assessment of these relationships [8]. Regarding water, difficulties can manifest as a result of individual stress that arises in playing roles based on their experiences. The roles and experiences related to water and sanitation can go beyond the physical inability to gain access to negotiations and the costs of obtaining them [10], [11].

Water-related stressors that cause psychosocial health problems can be categorized into four categories, namely financial or economic stress [11], [12], difficulty obtaining access to water [12]; [2], social stressors and stressors related to perceptions of injustice [13], [14], [15]. In the gender variable, an important and widespread concern is women's fear of sexual violence during water extraction, namely on the way to water sources [10]. Other psychosocial problems that are disproportionately felt by women include shame, shame, and distress when men peek or roam in the vicinity of defecation [16], [17]. Furthermore, it is known that concerns over sexual violence or rape are higher, frequent, and severe amongadolescents [18], [17]. There are also concerns about the restrictions on the time, how and where to defecate [14], [17]. For example, [17] reported that young girls face the sudden end of their freedom after marriage or during pregnancy, because they must negotiate a time and place for sanitation. In addition, 
women carrya disproportionate amount of stress than men in many situations. Based on this phenomenon, it is felt that itis important to explore more deeply the psychosocial health problems related to water supply and sanitation facilities.

The implication of this research is to provide recommendations for improving the conditions of water supply and sanitation facilities to pay more attention to the psychosocial health aspects of the community by respecting gender differences and the privacy of users of public facilities. Increasing efforts to maintain privacy and assisting in cooperation can be valuable inputs as implications for this research.

\section{Methods}

This qualitative research has been conducted using a phenomenological approach and determining the number of participants based on a purposive sampling technique, involving 5 families whose houses are close to the river. Informed consent was submitted before the study began, to explain the purpose of conducting the research and the importance of the role of participants in the study. Indepth interviews were conducted by the researcher at the participants' homes while observing the conditions of the residence as well as the participant's activities and field notes. In-depth interviews were recorded using a voice recorder, conducted 3 times to obtain data saturation and then triangulated between the data obtained through in-depth interviews, observations, and field notes. All research data are arranged in the form of a verbatim transcript. Each participant is given a $\mathrm{P}$ code followed by the participant numbering, so that all participants include P1 to P5. While the interview code is given the initials $\mathrm{W}$, which is also followed by the number of interviews: W1, W2, W3.

The transcript not only recorded the participants' utterances, but also documented all movements or nonverbal language. Efforts to gain the credibility of research results have been carried out by fulfilling the degree of trust, transferability, dependence, and certainty. Researchers have clarified the findings to participants after listening to the recorded interviews repeatedly and transcribing them into a verbatim transcript. Researchers show participants the results of data collection to obtain data accuracy and all transcripts have been approved by participants so that they do not change. In order to meet dependability, an audit is carried out by an expert in his/ her field in order to obtain data objectivity. Furthermore, the research data were analyzed simultaneously using Colaizzi analysis so that the meaning and process can be explained and to obtain the theme formulation of the research results. This research has been approved by the ethics committee of the Palembang Health Polytechnic.

\section{Results and Discussion}

\subsection{Results}

The following table shows the data on the characteristicsof the study participants.

Table 1. Characteristics of Research Participants

\begin{tabular}{ccccccc}
\hline No. & Code & Gender & Profession & Status & Age (yrs & Education \\
\hline 1 & P1 & Female & labour & wife & 35 & SMP \\
2 & P2 & Male & labour & husband & 40 & SMK \\
3 & P3 & Female & vendor & wife & 37 & SMP \\
4 & P4 & Female & labour & wife & 30 & SMA \\
5 & P5 & Male & Pedicab driver & husband & 35 & SMA \\
\hline
\end{tabular}

$\mathrm{F}=$ Female; $\mathrm{M}=$ Male SMP = Junior High School $;$ SMA = Senior High School

Based on the results of data collection, it is known that three of the five participants are housewives and not. While the other two participants are heads of families who work as pedicab drivers and laborers. Most of the participants came from a high school senior education background, so that participants' exposure to informal information, such as social media or other sources, was quite high. In other words, based on the level of education the participants showed that they could understand the importance of getting access to clean water and environmental sanitation. The age range of participants is 35-40 years old, besides that all participants are married and have children. In this age range, parents have entered adulthood and have certain developmental tasks related to work, education, and children's future as well as the economy.

The area where the participants live is inhabited by residents with middle to lower economic status. In general, based on the observations of researchers at the research site, in general, residents are in a financial condition full of limitations. They also live in areas that are very close to the river, some even have their houses above the river.

This condition appears to be considered as a condition that is used as a source of water for bathing or meeting drinking water needs. After the data collection was conducted, the researcher formulated four themes based on the interview excerpt in table 2 
below.

According to the results of the analysis using Colaizzi method, four main themes have been obtained, namely stress from not having access to clean water, economic difficulties cause emotional distress in acessing clean water, compulsion to use the available water, and the inconvenience of using public sanitation facilities. The theme of stress because it does not get access to clean water, arises because of the desire not to store river water as drinking water. The feeling of stress is also caused because there is no other option to consume drinking water sourced from the river. They realized that drinking water from the river was not a good thing, but because of the compulsion to use it, the river water was used as a source of drinking water. They realized that drinking water from the river was not a good thing, but because of the compulsion to use it, the river water was used as a source of drinking water. Often this condition burdens his mind so that it causes stress because he thinks about the impact as a result of consuming continuously.

Table 2. Interview Quotes and Themes

\begin{tabular}{|c|c|c|}
\hline No. & Interview quotes & Themes \\
\hline 1. & $\begin{array}{l}\text { - I'm worried if I keep drinking water from the river (P2 W2) } \\
\text { - I'm afraid if I drink this this water all the time,but I don't know how (P4 } \\
\text { W2) } \\
\text { - Horrified with anxiety if you continue to drink with the source from the } \\
\text { river (P5 W3) }\end{array}$ & $\begin{array}{l}\text { Stress from not } \\
\text { having accessto clean } \\
\text { water }\end{array}$ \\
\hline 2. & $\begin{array}{l}\text { - We have no money to buy food, how can wepay to get water (P1 W1) } \\
\text { - It's not certain that you can get money, it's hard to buy water (P5 W2) } \\
\text { - Like this, this is ourfinances, thinking thatwe can't pay the water } \\
\text { (P4 W1) }\end{array}$ & $\begin{array}{l}\text { Economic difficulties } \\
\text { cause emotional } \\
\text { distress in accessing } \\
\text { clean water }\end{array}$ \\
\hline 3. & $\begin{array}{l}\text { - There is no other choice, rather than not being able to drink water it is } \\
\text { getting more difficult (P3 W1) } \\
\text { - I don't know what to do with it, I installed it before but over time itgot } \\
\text { harder, I had to pay too (P4 W3) } \\
\text { - I don't know until whenit will continue, I don't know, forced to use river } \\
\text { water as a source of drinking water (P1 W1) }\end{array}$ & $\begin{array}{l}\text { Compulsion touse the } \\
\text { available water }\end{array}$ \\
\hline 4. & $\begin{array}{l}\text { - Shame if you must meet other people when going to the toilet, especially } \\
\text { if you meet fathers (P1 W2) } \\
\text { - Thinking if you want to defecate in a publictoilet, do you think there are } \\
\text { other people or not(P4 W3) } \\
\text { - I like it a bituncomfortable if I want to go to the bathroom, it's not good } \\
\text { with other people (P3 W3) }\end{array}$ & $\begin{array}{l}\text { The inconvenience of } \\
\text { using public } \\
\text { sanitation facilities }\end{array}$ \\
\hline
\end{tabular}

Emotional stress can also result from economic hardship. The difficulty of obtaining access to clean water can be caused by the inability of the economic aspect to obtain it. One participant said that he could not afford to buy clean water, let alone buy clean water, he couldn't afford to buy food. Participants prioritize buying food rather than buying clean water. This condition makes participants must use river water as a source of drinking water.

The theme was formed, namely the compulsion of participants to use water based on its availability, formulated based on the absence and difficulty of obtaining drinking water sources. One family even stated that they could not get access to clean water, so they were forced to use the available water. Even though the use of clean water for families is very important to fulfill basic human needs to maintain their health.

Another thing that causes psychosocial problems is discomfort when utilizing public facilities. Toilets made by the local community are used together. The benefits of the existence of public facilities cannot be denied anymore. However, the provision of public facilities is less concerned with the gender dimension. Participants said they were embarrassed to use the toilet, because there was likely no separation of toilets used by female or male residents. This condition causes discomfort and anxiety because female users are worried that someone will act indecently when using public toilets.

The results of observations carried out simultaneously with the implementation of in-depth interviews, the researcher displays the following figure which illustrates the use of water by the community. 


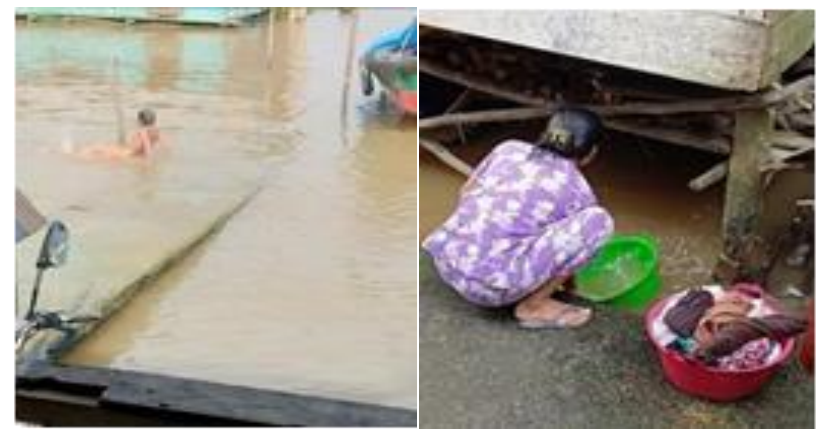

Figure 1

Use of river water

for bathing
Figure 2

use of river water for washing cutlery \& cooking

It appears that people still use unclean water sources to fulfill personal hygiene. Besides that, the local community also uses the water around their house, to pick up cutlery and cooking utensils.

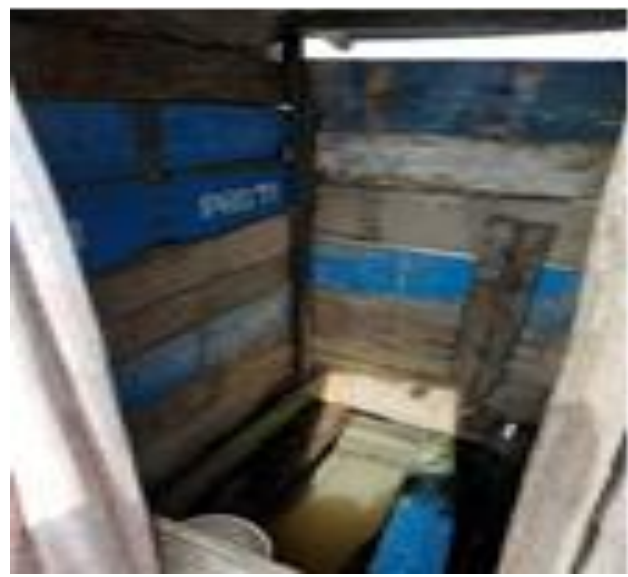

Figure 3. Public sanitation facilities

The public sanitation facilities are available, built-in moderation but pay less attention to user privacy. This condition makes women feel uncomfortable using these facilities. However, due to economic limitations, public sanitation facilities are still being used with full force. Furthermore, there is no differentiation of the toilet which is intended for men and women. This condition raises anxiety for women when using these facilities.

\subsection{Discussion}

Psychosocial health problems have long plagued the conditions of obtaining clean water and sanitation in certain community groups which are often neglected [19], [17], [12]. Stress as a sign of the emergence of psychosocial health problems is a common condition that often occurs in the fulfillment of water and sanitation, and if it is not immediately addressed it will have a negative impact on a person's quality of life [12]. In this study, the family felt that they had long experienced the complexity of getting clean water and it was often a topic of debate that had never been resolved. Various efforts have been discussed between community members and local community leaders, but the solution has not yet arrived.

The relatively low socio-economic conditions of the local community have resulted in difficulties in providing funds to obtain clean water and the inability to build sanitation facilities in their respective homes. In general, the participants work as laborers, and the wages they earn are only sufficient to meet makeshift food needs. In fact, water is a very basic human need. As according to Maslow's hierarchy of basic human needs, which places human physiological needs as the foundation of human needs in living their lives. In food processing, of course, must use water sources that meet health requirements.

The results of observations show that the respondent's residence is a semi-permanent house with very poor conditions. Since the announcement of the provision of clean water, the community has been very enthusiastic about obtaining the benefits of the provision of these facilities, but due to economic limitations, these facilities cannot be felt by all community groups. The provision of clean water by the city government of Palembang through a regional drinking water company (PDAM) has been able to reach most of the residential areas [20]. The city government also provides social rates for drinking water customers for houses of worship. Some poor households only use clean water during the dry season while during the rainy season they use rainwater because they do not have to pay fees. In addition, many poor families whose houses are in the tidal swamp area near the river are unable to install clean water from the PDAM. They only rely on the need for clean water from rainwater and rivers.

As stated by previous researchers, socioeconomic limitations are the majority inhibiting the fulfillment of this need [21], [2], [22]. Furthermore, socioeconomic conditions can also be affected by the total household members because it is assumed that a larger household is associated with competing needs, which leads to the possibility of experiencing emotional distress. This assumption is supported by another opinion, that in many cases, it is believed that difficulties in obtaining water can be part of the stress group associated with poverty [23], [24].

Stress in the social sphere is a problem that tends to affect social relationships and interactions at the household and community level. Some references even mention that related to sanitation, lack of privacy, fear of rape and sexual assault, fraud, conflicts in the use of public sanitation facilities and shame of not being able to provide toilet facilities are causes of social stress [5], [17], [18]. Women will feel embarrassed, tense and helpless when they meet men at the place of defecating [18]. Participants felt uncomfortable, which is said in the vocabulary of "uncomfortable, embarrassed" having to meet with the opposite sex when using public 
sanitation facilities. This fact shows that for women, the inconvenience factor is quite disturbing when using public facilities. In addition, participants felt disproportionate and heavier than men in many situations. The results of observations show that in some cases, public sanitation support locations (toilets) are located some distance from people's homes and consist of several rooms (cubicles) that are close to each other without separating the facilities designated for male and female residents. This fact has an impact on the inconvenience of women who use these facilities.

Although public sanitation support (toilets) is available, there are still other problems, namely the absence of clean water in public sanitation. Users of public toilets bring their own water from their homes or collect river water. Public sanitation does not have cleaning officers from residents but each user is obliged to maintain cleanliness.

The socio-cultural dimension that is reflected in the difficulty of obtaining water and sanitation practices through complex social interactions and relationships can create problems. The compulsion to consume the available water was also one of the conditions that had to be accepted by the participants and this was more often stated by female participants. Participants said that the current condition must be accepted because there is nothing else that can be done. Based on observations, it is known that most of them use river water as a source of drinking water, cooking, washing clothes, bathing and defecating. Psychosocial health and concern problems are often more intense or widespread among women. As [24], [25] explains that women who have the status of the head of the family feel more emotional pressure than male family heads. This is because women have to work harder to supervise children as well.

\section{Conclusion}

The complexity of water and sanitation issues is not as simple as one might think because it can have a negative impact on the psychosocial health of the family. Many factors have the potential to cause psychosocial problems, internal (stress and inconvenience) or external factors (economic and compulsion) in the family. A multisectoral approach is needed in developing public facilities by taking into account the psychological conditions of individuals and families.

It is recommended that a policy be made so that the construction of religious facilities in residential areas provides access to clean water from the PDAM, although it is limited based on the quota or time of water collection. The government provides convenience for poor families in obtaining clean water for drinking and cooking. It is necessary that the policy of making public sanitation (toilet) in residential areas must be separated (differentiated) between women and men.

\section{Acknowledgements}

Our gratitude goes to all parties for the support given to the implementation of this research. Participants, leaders of public health centers and community leaders who have contributed to provide valuable information for the continuity of this research. We also thank the leadership for their support so that this research can be carried out completely.

\section{References}

[1] I. Kusumawaty and A. Siswanto, "Air Bagi Kesehatan: Tantangan Serius Mewujudkan Tujuan Pembangunan Berkelanjutan Water for health : a serious challenge to realize sustainable development goals," pp. 52-59, 2019.

[2] E. G. J. Stevenson, A. Ambelu, B. A. Caruso, Y.Tesfaye, and M. C. Freeman, "Community water improvement, household water insecurity, and women"s psychological distress: An intervention and control study in Ethiopia," PLoS One, vol. 11, no. 4, pp. 1-13, 2016, doi: 10.1371/journal.pone.0153432.

[3] A. Wutich, "Intrahousehold disparities in women and men's experiences of water insecurity and emotional distress in urban Bolivia," Med. Anthropol. Q., vol. 23, no. 4, pp. 436-454, 2009, doi: 10.1111/j.15481387.2009.01072.x.

[4] A. Wutich, "the Effects of Urban Water Scarcity on Sociabilty and Reciprocity in Cochabamba, Bolivia," 2006.

[5] E. Bisung, S. J. Elliott, B. Abudho, C. J. Schuster-Wallace, and D. M. Karanja, "Dreaming of toilets: Using photovoice to explore knowledge, attitudes and practices around water-health linkages in rural Kenya," Heal. Place, vol. 31, pp. 208-215, 2015, doi: 10.1016/j.healthplace.2014.12.007.

[6] N. R. Krumdieck et al., "Household water insecurity is associated with a range of negative consequences among pregnant Kenyan women of mixed HIV status," J. Water Health, vol. 14, no. 6, pp. 1028-1031, 2016, doi: 10.2166/wh.2016.079.

[7] E. G. J. Stevenson et al., "Water insecurity in 3 dimensions: An anthropological perspective on water and women"s psychosocial distress in Ethiopia," Soc. Sci. Med., vol. 75, no. 2, pp. 392-400, 2012, doi: 10.1016/j.socscimed.2012.03.022.

[8] B. N. Krieger, "Epidemiology and the People "e s Health," Am. J. Epidemiol., vol. 175, no. 8, pp. 854-856, 2012.

[9] R. M. Sapolsky, "Social status and health in humans and other animals," Annu. Rev. 
Anthropol., vol. 33, pp. 393-418, 2004, doi: 10.1146/annurev.anthro.33.070203.144000.

[10] E. Bisung and S. J. Elliott, "It makes us really look inferior to outsiders: Coping with psychosocial experiences associated with the lack of access to safe water and sanitation," Can. J. Public Heal., vol. 108, no. 4, pp. e442- e447, 2017, doi: 10.17269/cjph.108.5546.

[11] E. Bisung and S. J. Elliott, "Psychosocial impacts of the lack of access to water and sanitation in low- and middle-income countries: A scoping review," J. Water Health, vol. 15, no. 1, pp. 17-30, 2017, doi: 10.2166/wh.2016.158.

[12] A. Wutich and K. Ragsdale, "Water insecurity and emotional distress: Coping with supply, access, and seasonal variability of water in a Bolivian squatter settlement," Soc. Sci. Med., vol. 67, no. 12, pp. 2116-2125, 2008, doi: 10.1016/j.socscimed.2008.09.042.

[13] M. A. Hanjra and M. E. Qureshi, "Global water crisis and future food security in an era of climate change," Food Policy, vol. 35, no. 5, pp. 365-377, 2010, doi: 10.1016/j.foodpol.2010.05.006.

[14] A. Nallari, “,All we want are toilets inside our homes!ee: The critical role of sanitation in the lives of urban poor adolescent girls in Bengaluru, India," Environ. Urban., vol. 27, no. 1, pp. 73- 88, 2015, doi: $10.1177 / 0956247814563514$.

[15] A. Wutich, M. Beresford, and C. Carvajal, "Can Informal Water Vendors Deliver on the Promise of A Human Right to Water? Results From Cochabamba, Bolivia," World Dev., vol. 79, pp. 14-24, 2016, doi: 10.1016/j.worlddev.2015.10.043.

[16] S. Hirve et al., "Psychosocial stress associated with sanitation practices: Experiences of women in a rural community in India," J. Water Sanit. Hyg. Dev., vol. 5, no. 1, pp. 115-126, 2015, doi: 10.2166/washdev.2014.110.

[17] K. C. Sahoo et al., "Sanitation-related psychosocial stress: A grounded theory study of women across the life-course in Odisha, India," Soc. Sci. Med., vol. 139, pp. 80-89, 2015, doi: 10.1016/j.socscimed.2015.06.031.

[18] K. R. S. Hulland et al., "Sanitation, stress, and life stage: A systematic data collection study among women in Odisha, India," PLoS One, vol. 10, no. 11, 2015, doi: 10.1371/journal.pone.0141883.

[19] V. Khawas, Human Development Report 20052006, vol. 36, no. 3. 2006.

[20] S. M. Aisyah, N. A. Supli, and A. H. Z. Tarigan, "Peran Strategis City Diplomacy Pemerintah Palembang Dalam Mewujudkan Kota Berkelanjutan Ramah Lingkungan," Dauliyah J. Islam. Int. Aff., vol. 5, no. 1, p. 125, 2020, doi: 10.21111/dauliyah.v5i1.4277.

[21] P. Henley et al., "Cultural and socio-economic conditions as factors contributing to chronic stress in sub-saharan African communities," Can.J. Physiol. Pharmacol., vol. 92, no. 9, pp. 725-732, 2014, doi: 10.1139/cjpp-2014-0035.

[22] G. H. Zamani, M. J. Gorgievski-Duijvesteijn, and K. Zarafshani, "Coping with drought: Towards a multilevel understanding based on conservation of resources theory," Hum. Ecol., vol. 34, no. 5, pp. 677-692, 2006, doi: 10.1007/s10745-006- 9034-0.

[23] C. L. Workman and H. Ureksoy, "Water insecurity in a syndemic context: Understanding the psycho-emotional stress of water insecurity in Lesotho, Africa," Soc. Sci. Med., vol. 179, pp. 52-60, 2017, doi: 10.1016/j.socscimed.2017.02.026.

[24] A. Wutich and A. Brewis, "Food, water, and scarcity: Toward a broader anthropology of resource insecurity," Curr. Anthropol., vol. 55, no. 4, pp. 444-468, 2014, doi: 10.1086/677311.

[25] W. E. Jepson, A. Wutich, S. M. Colllins, G. O. Boateng, and S. L. Young, "Progress in household water insecurity metrics: a crossdisciplinary approach," Wiley Interdiscip. Rev. Water, vol. 4, no. 3, p. e1214, 2017, doi: $10.1002 /$ wat 2.1214 